\title{
TÉCNICA DA COMPLEMENTAÇÃO DE FRASES COMO RECURSO PARA EXPRESSÃO VIVENCIAL DO ALUNO EM VÉSPERA DE PROVA
}

\author{
Edna Paciência Vietta*
}

VIETTA E. P. et al. Técnica da complementação de frases como recurso para expressão vivencial do aluno em véspera de prova. Rev.latino-am.enfermagem, Ribeirão Preto, v. 4, nº especial, p. 39-49, abril 1996.

O presente artigo avalia a estratégia alternativa de integração em grupo por meio da aplicação da técnica da complementação de frases em Universitários, em véspera de prova. Teve como objetivo: a) oferecer aos alunos do curso de graduação em enfermagem da Escola de Enfermagem de Ribeirão Preto da Universidade de São Paulo, uma possibilidade de expressão vivencial da situação peculiar; b) apreender suas condições emocionais relacionadas às suas expectativas; $c$ ) identificar aspectos possíveis de serem manejados e; d) sugerir uma possível alternativa de intervenção para alívio de tensões.

UNITERMOS: técnica da complementação de frases, alunos de graduação em enfermagem condições emocionais do aluno de graduação

\section{INTRODUÇÃO}

Segundo ROTTER \& $\mathrm{HOCHREICH}^{8}$, as técnicas projetadas são utilizadas a fim de evitar limitações de relatos pessoais como também para atingir motivações inconsistentes em lugar de traços e atitudes superficiais. Utiliza-se para avaliação

\footnotetext{
* Renata C. Labate; Maria C. Moraes; Antonia R. F. Rodrigues; Jani Cristina; Eliana Ap. P. S. Braga. Docentes do Departamento de Enfermagem Psiquiátrica e Ciências Humanas da Escola de Enfermagem de Ribeirão Preto da Universidade de São Paulo
} 
avaliação e de pesquisa de personalidade, caracterizando-se como um instrumento de ampla aceitação e de aplicação abrangente em nível pedagógico e terapêutico difere das demais técnicas, pois, sua aplicação é informal e sua avaliação e interpretação, são mais subjetivas. Normalmente pede-se ao sujeito que cumpra uma tarefa simples, porém imaginativa, como desenhar, completar frases incompletas, contar estórias sobre algumas gravuras, ou ainda relatar as associações evocadas a partir de estímulos específicos. Presume-se que, nas técnicas, o que o sujeito produz, seja em termos de organização ou de imaginação, revela características importantes e estáveis de sua própria personalidade, bem como a liberação de expressões vivenciais significativas para a compreensão de seu comportamento (BROWN \& PEDDER ${ }^{1}$ ).

No presente utilizamo-nos da técnica de complementação de frases como recurso a ser utilizado para expressão vivencial do aluno em véspera de prova. Sabe-se que a expectativa do mesmo em períodos que antecedem um exame é caracterizado por sentimentos e emoções diversas, traduzidas em seu comportamento levando o estudante a reações de luta ou fuga, quer motivando-o ao estudo e esforço para obter bons resultados, quer adotando mecanismos mentais diversos, como por exemplo, a negação e as fantasias. Na fantasia, a pessoa substitui as situações reais por uma situação mais agradável, satisfatória ou gratificante criada por ela mesma, enquanto que a negação envolve uma espécie de pensamento mágico, no qual a pessoa imagina que o que quer que esteja causando ansiedade, não existe efetivamente (IRVING ${ }^{6}$ ).

Sabe-se que o aluno nem sempre encontra-se emocionalmente estável para enfrentar o dia-a-dia escolar, não tendo nenhum contexto apropriado para expressar suas emoções, sendo que este, um dos motivos de prejuízo em seu rendimento escolar. Observa-se ainda que os indivíduos reagem de maneiras diferentes diante dos insucessos da vida. Um fracasso em uma tentativa pode deixar esperança de êxito em outra, ou estimular para uma nova alternativa. Porém, o fracasso sob forma de frustrações freqüentes e repetidas, no começo de uma carreira, faz baixar não só o nível de expressão como o de aspiração dos indivíduos. Nesse sentido, devemos levar a sério o êxito do aluno que inicia um curso, a fim de que não haja abatimentos, desânimos e conseqüentes desinteresses, baixo aproveitamento ou até mesmo a evasão.

Pensando nisso, a coordenação da disciplina de "Integração do Estudante de Enfermagem na Escola e na Profissão", oferecida no primeiro semestre do curso de graduação em enfermagem da Escola de Enfermagem de Ribeirão Preto Universidade de São Paulo assumiu o compromisso de trabalhar com os alunos em períodos considerados críticos em termos de tensão como, por exemplo, o da véspera de provas, o início de estágios, aplicação de determinadas técnicas de enfermagem, entre outros. O presente estudo foi desenvolvido na situação específica de véspera de prova com os seguintes OBJETIVOS: oferecer ao jovem universitário um espaço para expressão vivencial nessa circunstância; aprender as condições 
emocionais do jovem universitário relacionados às suas expectativas e identificar, através da aplicação da técnica de complementação de frases, aspectos passíveis de serem manejados em uma possível intervenção para alívio de tensões.

\section{METODOLOGIA}

População: 17 alunos universitários integrantes de um grupo de vivência da disciplina de "Integração do Estudante de Enfermagem na Escola e na Profissão".

\section{PROCEDIMENTO}

A técnica de complementação de frases foi aplicada a esse grupo de alunos em véspera de prova de Bioquímica, aos quais solicitou-se que fossem complementando por escrito as frases estímulos ditadas pela professora.

As frases estímulos foram apresentadas na seguinte ordem: "Toda vez que" "Se eu pudesse...", "Bom mesmo seria...", "Mas quando menos se espera...", "Agora, se é uma coisa que eu não aceito...", "Mas eu sei que a vida não é só...", "Para dizer a verdade eu nunca...", "Porque acima de tudo...". Foi ainda reservado um espaço para observações livres dos alunos sobre o procedimento em questão.

Aos sujeitos não foi explicitado o real objetivo do exercício, embora os alunos tenham sido estimulados a extravasarem livremente suas emoções e sentimentos de forma a complementar as frases atribuindo-Ihes sentido. Foi-lhes apresentado oito frases incompletas, para cuja complementação foi reservado um período de 45 minutos.

Assim, de posse do conteúdo obtido por todos os sujeitos em relação a cada uma das frases estímulo procedeu-se a categorização através dos seguintes passos:

1 - Uma leitura cuidadosa do conteúdo total de forma a apreender o seu significado dentro da estrutura global e temática, visando a apreensão unívoca do tema em sua contextualidade.

2 - Agrupamento das complementações elaboradas pelos sujeitos, classificados por ordem de resposta (índices de significância), categorizadas segundo as frases estímulos (unidades de codificação). Unidades estas apreendidas por meio de um processo mental seletivo-associativo como ênfase em aspectos dinâmicos. 
3 - Análise compreensiva do conteúdo manifesto, procurando evidenciar a natureza e as forças dinâmicas relativas às frases estímulos a que foram submetidos os sujeitos.

Segundo LOFLANDRE ${ }^{7}$, estudioso da metodologia qualitativa, a categorização é um recurso imprescindível para garantia do rigor metodológico, e certamente um procedimento a ser amplamente exigido em pesquisas desta natureza é que utilizamos neste trabalho os passos do método fenomenológico sugerido por $\mathrm{GIORGI}^{5}$ (para cujo aprofundamento sugerimos a obra original do autor), adaptado para o presente estudo.

Entendendo como $\mathrm{CHIZZOLI}^{3}$, que a pesquisa é uma criação que mobiliza a criatividade inventiva do pesquisador, sua habilidade artesanal e sua perspectiva para elaborar metodologias apropriadas é que buscamos respaldo em GIORGI ${ }^{5}$, especialmente, e de forma restrita, aos passos essenciais de referido método conforme descrito por este. Tal estratégia visou, unicamente, garantir o rigor exigido em pesquisas desta natureza, sem no entanto, aprofundarmos no método em si.

O que GIORGI ${ }^{5}$ descreve como passos essenciais do método fenomenológico, corresponde no nosso entender e, em última análise, ao processo de estabelecimento de categorias dos métodos qualitativos de modo geral, assim, apreendidos da definição de $\mathrm{GIL}^{4}$, como a organização do conteúdo apreendido em sua significação global, agrupamento e seleção de elementos significativos (ou unidades de significados) orientado por um único princípio de classificação, segundo regras básicas, fundamentadas num determinado referencial (que pode ser fenomenológico ou não). Esse procedimento assim especificado propicia a síntese do conteúdo, favorecendo a análise compreensiva do fenômeno.

\section{ANÁLISE DOS RESULTADOS}

Os dados obtidos foram submetidos à análise compreensiva de base dinâmica, a partir das categorias de estímulos (frases incompletas) na ordem em que foram apresentadas pelos sujeitos.

\section{- Referente à complementação da frase: "Toda vez que..."}

Embora os alunos não soubessem o verdadeiro objetivo do exercício, houve um direcionamento das respostas voltadas para a expectativa diante da prova a ser realizada no dia posterior. As frases significativas relacionadas à temática revelaram estados de preocupação, irritação, expectativa, ansiedade, sentimentos 
e incapacidades verbalizadas por preguiça, sensação de não dar conta da matéria, não pensar em outra coisa senão na prova, sensação de que não sabe nada. Esses estados podem influir, de alguma forma, na concentração do aluno e na sua disposição para os estudos, instalando-se assim uma fadiga compensatória (apatia) como fuga para justificar seu comportamento. Isto pode provocar aumento do nível de tensão dos alunos, uma vez que a tensão normal não tenderia a simples adoção de mecanismo de defesa, mas sim a concentração de esforços com manifestação de segurança.

A fantasia faz parte do mecanismo de ajustamento. É a fuga de uma situação incômoda. No entanto é importante dizer que os mecanismos de defesa, quando empregados com medida são, não só normais, como também necessários para se manter o equilíbrio emocional. A complementação das frases revelou ainda uma certa conscientização da necessidade de estudar (um sentimento de realidade) e até mesmo a manifestação de "pânico" expressa pelo aluno na complementação de frases relacionadas a sua expectativa diante da prova. Essas expressões identificadas como indicadores da presença de tensões parecem ser o indício da necessidade de uma intervenção com vista à melhoria do rendimento escolar. Como o aluno encontra-se em conflito entre a vontade ou não de estudar e a necessidade ou disposição em fazêlo, estará também mais vulnerável e, portanto, mais suscetível à aceitação de ajuda. “... que tem prova, não durmo direito, minha preocupação é maior que minha vontade de estudar”, “... vou estudar sinto preguiça e acho que não vou dar conta da matéria, fico preocupada tensa e não consigo me concentrar", “... tenho prova fico preocupada na expectativa do que vai acontecer. Não penso noutra coisa. Só na prova”, "... eu estudo fico irritada, porque parece que não sei nada”, “... tenho provas e eu não estudo direito, entro em pânico. Também é isto que dá deixar a matéria acumular, não vou dar conta mesmo. Quem sabe um dia aprendo", “... penso no que pode acontecer sinto cala-frios e lima ansiedade me invade pela expectativa deste momento. Eu fico muito tensa e apreensiva".

\section{- Referente à complementação da frase: "Se eu pudesse..."}

Um certo grau de tensão como resultado da situação de ansiedade e expectativa, mais o conflito entre estudar e não estudar, acrescido ainda das expectativas de não obter uma boa nota, leva o jovem diante do comportamento de luta ou fuga. Os sujeitos pesquisados adotaram mecanismos mentais ou de defesas, tais como as fantasias e a negação. Como defesa contra a ansiedade ou para esconder motivações inconscientes, o jovem idealiza a experiência. Por exemplo, a manifestação da vontade de "estar longe", "em outro lugar", "em poder captar tudo o que o professor diz na aula", "voar", "ir para todos os cantos do mundo sem precisar estudar", "ir para casa", "parar o relógio" é representada por uma concepção mágica de soluções de problemas. Revela ainda uma certa "regressão" 
em termos de dependência, detectada através de sentimentos de "saudade dos pais", "do gatinho", "da cama", "da comida gostosa da mãe" e "da priminha".

Um certo grau de ansiedade é natural, saudável e até necessário. Natural e saudável, porque corresponde a uma realidade: há o desejo de sair-se bem na prova e o esforço para tirar uma boa nota, de outro, há a evidente incerteza do resultado (desejo $\mathrm{x}$ incerteza $=$ ansiedade). Além disso, um certo nível de ansiedade e tensão é útil e necessária, pois, mantém o indivíduo atento ou alerta para o fato de que tem que estudar, facilitando assim a concentração de esforços. No entanto, a ansiedade pode alcançar níveis muito altos e provocar tensões difíceis de suportar. Neste caso, o jovem, lança mão de mecanismos de defesa para aliviar a tensão.

\section{- Referente à complementação da frase: "Bom mesmo seria..."}

Os alunos dizem que bom mesmo seria "se soubessem tudo sobre a prova", "que lhes garantisse uma nota de nível razoável", "se pudessem passar de ano ou se tirassem $10 \mathrm{em}$ todas as provas", "se pudessem mudaras coisas, torná-las mais fáceis se tivessem resolvido todos os seus problemas". Os sujeitos referemse aos estudos e as outras obrigações impostas por regras que bem poderiam ser eliminadas. O desejável seria: "saber tudo sobre a prova", poder viver viajando, gastando e se divertindo", "não precisar levantar às 7 horas da manhã para fazer educação física", "passar de ano simplesmente", "estar de férias", "descobrir que o caminho é tão fácil de ser alcançado e os objetivos de serem atingidos", "não ter mais nada que o aflija”, numa perspectiva de solução mágica.

A liberdade de expressão parece liberar o aluno de suas opressões, levando-o a extravasar seus desejos e prazeres mesmo que por um lapso de tempo. Pensa-se que essa necessidade, se bem trabalhada, leva o jovem a uma maior conscientização da realidade, alivia as ansiedades favorecendo seu aproveitamento nos estudos.

Sem dúvida, o sentimento que gera maior insegurança advém do fato do jovem universitário se sentir real ou imaginariamente cobrado ou na expectativa de cobrança por parte da família e ou sociedade, em termos de sucesso, e da sensação de fracasso conseqüente de sentimentos de culpa e perda de auto-estima. Desse modo evidencia-se a importância de trabalhar esses sentimentos preventivamente.

\section{- Referente à complementação da frase: "Mas quando menos se espera..."}

Ao mesmo tempo em que o aluno sonha e parece otimista com sua situação, busca, na fantasia, encontrar soluções mágicas para alívio de suas tensões e ansiedade. O aluno revela a consciência de seus problemas reais e concretos, porém, mostra uma certa ambivalência, revelando pessimismos, revoltas e rebeldias diante do inevitável confronto da fantasia com a realidade. Ao completar a frase 
“... mas quando menos se espera...", o jovem diz, "aquela estrela aparece brilhante pronta para me ajudar...", “... mas quando menos se espera estaremos formadas e exercendo a profissão", “... quando menos se espera aparecem indivíduos que acabam com os nossos sonhos, com a liberdade, com a esperança e com o amor", "... quando menos se espera sempre aparece alguma coisa para fazer-nos acordar para a vida, por os pés no chão e acabam com os nossos sonhos, devido a dureza da realidade que teremos que enfrentar", "...mas quando menos se espera surge alguém para nos chamar à responsabilidade”, “...mas quando menos se espera aparece alguém para nos cobrar alguma coisa".

$\mathrm{Na}$ verdade os sujeitos pesquisados expressaram expectativas ora pessimistas, ora otimistas, ora ainda, realista, em um esforço sadio de integração.

- Referente à complementação da frase: "Agora, se é uma coisa que eu não aceito..."

Em períodos de conflitos como os aqui mencionados, o aluno, se desvela e manifesta certas aversões e descontentamentos contra tudo que não é "elevado" como a ambição, o egoísmo da humanidade, a sonegação, a mesquinhez, a falsidade, o orgulho, destacando o valor das virtudes e da liberdade. Faz denúncias e condena a submissão, a traição e a injustiça. Com isso parece mais predisposto a auto avaliação. Os sentimentos provocados pela expectativa o impele a admitir fora de si, sentimentos negativos, em uma mistura de projeção e racionalização.

Diz, ainda, "não aceitar a dificuldade de captação da matéria...", "ter prova na sexta-feira e ter que fazer resumo de Saúde Pública..." em uma atitude de autojustificativa de seu despreparo. Aparece também a necessidade de assunção e consciência de responsabilidade por seus atos, “... que me chamem de lunática, irresponsável, tenho plena consciência de tudo o que acontece ao meu redor e das minhas atitudes". Há, ainda, a tendência ou o esforço em se mostrar autêntico e firme em seus pontos de vista "... eu mostro a cara quando não aceito algo, e brigo feio se tiver certeza que estou certo".

- Referente à complementação da frase: “Mas, eu sei que a vida não é só...”

O aluno parece motivado a reflexão, não se mostra alienado e pondera sobre os prós e os contras de sua situação existencial. Busca dar sentido à vida, consciente de que, se há tristezas e decepções, há também alegrias, carinho e compreensão. Acredita no livre arbítrio, assumindo uma posição de responsabilidade pelo próprio destino... "a vida pode ser o que quisermos, desde que trabalhemos duro em cima de nossos ideais". Embora lute por uma vida plena de prazeres admite "que a vida não é só um mar de rosas", "... e o que se consegue de forma muito fácil não tem graça". Parece alerto e preocupado com o futuro e sente a necessidade de conciliar obrigações e lazer "a vida não é só brincadeiras, temos que ter um ideal em nossas vidas, temos que pensar o que seremos no futuro". 
Porém, percebe-se um misto de ambivalência normal e sadia. Há aqueles que dizem "que a vida não é só estudar..." "é cheia de encantos e magia, é só descobri-los e curti-los ao máximo, cada minuto..." "a vida é curta minha gente, vamos aproveitá-la". No fundo, o aluno, luta por um futuro melhor e aspira a realização.

\section{- Referente à complementação da frase: "Para dizer a verdade eu nunca..."}

Após as reflexões anteriores, os alunos, parecem cair em si e expõem seus sentimentos de arrependimento, de culpa, de perda e de dúvidas sobre a própria vida e situação atual e a vivência do momento. Manifestam a necessidade de serem mais originais mais autênticos. Aparece ainda um senso de responsabilidade pelos atos... "para dizer a verdade nunca seria capaz de fazer alguma coisa errada, sem sentir-me culpado...”, “... nunca estive com tantas dúvidas sobre a minha vida como estou neste momento", “... eu nunca fui tão desleixada com o estudo, como estou agora, neste começo de ano", “... eu nunca me dei conta de que eu estou me prejudicando", “... eu nunca me enganei tanto".

A culpa é o sentimento de ser indigno, mau, ruim, cheio de remorsos, autocensurável. Estes sentimentos relacionados à situação de expectativa da prova faz sentido, principalmente, quando o aluno não se sente suficientemente preparado. Não obstante, por mais que estude há sempre a incerteza e a expectativa de surpresas.

Por outro lado, o grau de culpa é variável de pessoa para pessoa, e se o sentimento de culpa em alto grau é preocupante a ausência total de culpa é tão ou mais grave dependendo do grau de responsabilidade e maturidade envolvida.

- Referente à complementação da frase: "Porque acima de tudo..."

Os sujeitos mostram que acima de tudo têm uma meta a atingir e um propósito ou sentido de vida a alcançar... "Viver bem, com muita harmonia, conseguir se formar em Enfermagem na USP”, “... poder trabalhar”, “... fazer amigos e conhecer outros países”, “... é conseguir se formar exercera profissão, casar, ter filhos e viver feliz para sempre", “... é executar uma missão seja ela qual for". Porém, lembram que a recompensa vem com o esforço e perseverança.

\section{CONCLUSÕES}

O presente estudo mostrou que, a técnica da complementação de frases, é uma alternativa para estimular os alunos a liberarem suas emoções relacionadas às expectativas de prova e, portanto um espaço para a liberação vivencial dos universitários nestas circunstâncias. 
O contexto em que se desenvolve a técnica, ou seja, um ambiente descontraído e informal, e as condições favoráveis de motivação (interação grupal) que se instala, favorece a liberação da expressão vivencial do aluno.

Fica claro que, o período que antecede uma prova, pode ser considerado crítico pelas indicações de ansiedade, constatados no presente estudo.

A ansiedade diante da situação de expectativa da prova leva o aluno a reações de luta ou fuga, e a adotação de mecanismos nem sempre adequados e suficientes para o alívio de suas tensões.

Percebe-se que elevação contínua dessas tensões influi, de alguma forma, na concentração de esforços e na disposição do aluno para o estudo, e enfrentamento de situação peculiares.

Dependendo de como esses aspectos são trabalhados, poderão contribuir para um maior aproveitamento do aluno, ou para o prejuízo de seu rendimento escolar.

Os aspectos a serem trabalhados foram identificados como: ansiedade, expectativa e culpa, bem como os mecanismos de defesa utilizados pelos alunos, sobretudo, a fantasia, projeção e regressão.

A medida em que o aluno extravasa seus sentimentos e emoções de certa forma ele se alivia conforme pudemos evidenciar pelas observações finais registrada pelos alunos.

"Este tipo de exercício nos leva a refletir sob nossas atitudes e nos torna mais tranqüilos para enfrentarmos nossas responsabilidades".

"Alivia nossas tensões e medos até mesmos irracionais".

"A gente acaba percebendo que a preocupação impede que tomamos a decisão certa como, por exemplo, estudar ou ficar calmo, seja qual for a situação ou o resultado".

"Nos dá uma certa tranqüilidade pensar... Puxa! Se eu estudei não tenho o que temer... dá até para encarar numa boa".

"Me faz lembrar que em situações de tensão não consigo nem mesmo estudar; perco a fome, desanimo e já venho para a prova, arrasado...".

"Seria bom que a gente tivesse mais oportunidades como estas, sempre ajuda".

"Bem, acho que ainda dá tempo para estudar um pouco".

A aplicação da técnica como objeto intermediário, estabelece possibilidades de intervenção preventiva mostrando ser um recurso utilizável em situações de "crise" demonstrando ser propício para alívio de tensões e mobilização de recursos adaptativos à situação apresentada.

Fica claro ainda que, o período que antecede uma prova pode ser realmente um momento crítico, no qual, ao mesmo tempo em que o aluno necessita de ajuda está conforme assinala CAPLAN ${ }^{2}$, mais acessível e vulnerável a este tipo de intervenção.

Sugestão: que as escolas de um modo geral, estejam atentas para a 
necessidade de trabalhar estas questões de forma pedagógica e criativa. A oportunidade oferecida ao aluno de expressar-se através da técnica de complementação de frases, num contexto de motivação favorável, pode ser uma das alternativas para se trabalhar as tensões e melhorar a sua produtividade, conforme opinião do próprio aluno.

\section{TECHNIQUE OF COMPLEMENTING SENTENCES AS A RESOURCE TO STUDENTS EXPRESSION IN THE DA Y BEFORE THEIR EXAMINATION}

This article evaluates an alternative strategy of group intervention using the technique of complementing sentences to a group of students at University just before their examination. It aimed at offering to the nursing undergraduate students from the College of Nursing at Ribeirão Preto - University of São Paulo, a space to show their feelings related to this peculiar situation. The authors searched to catch the students' emotional conditions regarding their expectations as well as to identify possible aspects that can be handled looking at suggesting alternatives of intervention to alleviated tension.

UNITERMS: technique of complementing sentence, nursing undergraduate student, students' emotional condition

\section{TÉCNICA DE LA COMPLEMENTACIÓN DE FRASES COMO RECURSO PARA EXPRESIÓN VIVENCIAL DEL ALUMNO EN LA VÍSPERA DE EXAMEN}

El presente artículo, evalúa la estrategia alternativa de la intervención en grupo mediante la técnica de la complementación de frases en Universitarios, en el día anterior de a pruebas de conocimientos. Tuvo como objetivos: a) ofrecer a los alumnos del curso de pre-grado en enfermería de la Escuela de Enfermería de Ribeirao Preto USP, una posibilidad de expresión vivencial en situación específica; b) captar sus condiciones emocionales relacionadas a sus expectativas; c) identificar aspectos posibles de ser manejados y; de sugerir una posible alternativa de intervención para alivio de sus tensiones.

UNITERMOS: técnica de complementación de frases, graduados en enfermería, condiciones emocionales de los alumnos graduados 


\section{REFERÊNCIAS BIBLIOGRÁFICAS}

01. BROW, D.; PEDDER, J. Introdução à psicoterapia. Rio de Janeiro: Editora Campus, 1981. p. 179.

02. CAPLAN, G. Princípios de psiquiatria preventiva. Buenos Aires: Paidós, 1966. p. 306.

03. CHIZZOLI, A. Pesquisa em ciências humanas e sociais. São Paulo, 1991. p. 163.

04. GIL, A. C. Métodos e técnicas de pesquisa social. São Paulo: Cortez, 1991. p. 163.

05. GIORGI, A. Phenomenologia and psycological research. Pittsburg: Duchesne University Press, 1985. p. 89.

06. IRVING, S. Enfermagem psiquiátrica básica. 2. ed. Trad. Fernando Diniz Mundem e Maria Dolores Lins de Andrade. Rio de Janeiro: Interamericana, 1979. p. 292.

07. LOFLANDRE, J. Analyzing social seltings. Beaumont, Ca Wadsworth, 1971. p. 213.

08. ROTTER, J. B.; HOCHREICH, D. J. Personalidade. Rio de Janeiro: Interamericana, 1980. p. 137. 